García Perera, José.

Profesor, Universidad de Sevilla, Departamento de pintura, grupo HUM-864 Observatorio del Paisaje.

\title{
La herida y el píxel. La desmaterialización del cuerpo pictórico en la era digital.
}

\author{
TIPO DE TRABAJO \\ Comunicación. \\ PALABRAS CLAVE \\ Cuerpo, error, materia, digital.
}

KEY WORDS

Body, glitch, matter, digital.

RESUMEN

La cultura digital está implantando la desmaterialización en numerosas facetas de nuestra vida, y el arte no puede escapar de este influjo. La carnalidad hiriente que alcanzaba la representación pictórica del cuerpo a mediados del siglo XX ha dejado sitio para un nuevo cuerpo fragmentado que se acerca a la estética del fallo digital del arte glitch. El presente estudio documental se centra en el último estadio de la evolución de este icono pictórico en su degradación, permitiéndonos reflexionar acerca de cómo la pintura reciente refleja los cambios que se producen en la sociedad actual, y de cómo el cuerpo pictórico responde a verdades de nuestro ser. El fallo se revela hoy como un respiro dentro de un entorno marcado por el ansia de perfección; es el accidente que destapa el artificio de la sobrecarga de imágenes que nos mantiene aletargados en una existencia de simulaciones.

\section{ABSTRACT}

Digital culture is introducing dematerialization in many facets of our life, and art can not escape this influx. The hurtful carnality reached by the pictorial representation of the body in the middle of the twentieth century has left room for a new fragmented body that approaches the aesthetics of digital glitch art. This documentary study focuses on the latter stage of the evolution of this pictorial icon in its degradation, allowing us to reflect on how the recent painting reflects the changes that happen in today's society, and how the pictorial body responds to truths of our being. Glitch is revealed today as a break in an environment marked by the desire for perfection; is the accident that uncovers the artifice of the overload of images that keeps us in a lethargic existence of simulations.

\section{INTRODUCCIÓN}

A lo largo de todo el siglo XX hemos podido asistir a la desestabilización progresiva de la imagen del cuerpo en la pintura. Los desastres de la Segunda Guerra Mundial avivaron un talante destructor que se extiende como una verdadera epidemia en muchas de las manifestaciones artísticas del momento. Las experiencias de la bomba atómica y los campos de exterminio hacen de la destrucción significante y significado: una nueva imagen del cuerpo surge por medio de una materia pictórica densa y convulsa que no puede eludir el sufrimiento ${ }^{1}$. La pintura, que antes pintaba la piel, se ha desnudado; ahora pinta la carne expuesta a través de la herida ${ }^{2}$. Figuras clave de mediados del siglo XX dan forma a criaturas degeneradas en las que no puede dejar de verse un reflejo de las atrocidades que el ser humano ha sido capaz de cometer contra su propia corporeidad.

\footnotetext{
${ }^{1}$ Calvo, Francisco et al: Pintura al desnudo. Picasso, Dubuffet, de Kooning, Bacon, Saura. Fundación BBVA, Bilbao, 2001.

${ }^{2}$ Barro, David et al: Muestra la herida. La enfermedad. Arte y medicina 1. Fundación Luis Seoane, La Coruña, 2010.
} 
En décadas siguientes, con la fotografía, el cine y, especialmente, con el auge del arte de acción, podrá hablarse de una nueva estética de la carne que alcanza la abyección absoluta, empeñándose en mostrar la herida hasta la náusea, golpeando al espectador al quebrantar la barrera de ese desinterés estético que separa la imagen real de la imagen artística. Los relatos de enfermedad -el cáncer y el sida revolucionaron la cultura de fin de siglo-, así como los debates en torno a la cirugía y la manipulación genética, no han hecho sino poner en cuestión la identidad de este cuerpo que con plena conciencia debe ser menos estable que nunca, más mutable, menos bello ${ }^{3}$. Así, Hal Foster nos advierte de que para muchos "en la cultura contemporánea la verdad reside en el sujeto traumático o abyecto, en el cuerpo enfermo o dañado. Sin duda, este cuerpo constituye la base de prueba de importantes atestiguaciones de la verdad, de necesarios testimonios contra el poder" ${ }^{4}$.

Siguiendo la trayectoria de este cuerpo violentado cabe preguntarse acerca de la desmaterialización que el mundo digital ha implantado en diversas facetas de nuestra vida ¿Dónde está la verdad del ser en este nuevo contexto cargado de simulaciones? Ante la carnalidad hiriente que imponía el arte a finales del siglo pasado ha surgido en la pintura otro cuerpo mutilado más bien por distorsión, por interferencia, por baja resolución, por pixelado; es la herencia de ese arte glitch que ha desembocado en una sublimación estética del error digital.

Este trabajo reflexiona sobre las implicaciones de esta transformación en el icono pictórico del cuerpo: de la pintura del drama corpóreo a la del borrón virtual, imagen de otra imagen, ilustrativa de nuevos modos de experimentar nuestra fisicidad misma. Su discusión principal no se desarrolla por tanto en la distancia que separa la pintura del arte digital, sino que permanece en el ámbito de la primera con idea de indagar en cómo los nuevos medios a nuestro alcance han configurado visiones y lecturas inéditas indispensables para comprender el rumbo que están tomando los discursos pictóricos más recientes. La noción de desmaterialización presente en el título, conviene aclararlo, no pretende definir una tendencia predominante, sino simplemente destacar lo que consideramos uno de los fenómenos fundamentales de aquellos que conviven en el panorama caleidoscópico de la pintura actual. La herida real sigue vigente en la pintura -ahí está, entre otros, Jenny Saville-, pero en esta historia de la anomalía corporal es necesario destacar la invasión del píxel como episodio relevante. La investigación llevada a cabo, de carácter documental, propone un análisis cualitativo e interpretativo del contexto de este nuevo cuerpo degradado y de algunas estrategias singulares que merecen ser resaltadas. Las conclusiones finales tratarán de esbozar el porqué de esta pintura emparentada con lo digital y de unos cuerpos alejados de su plenitud, teniendo siempre en cuenta como espejo esa otra vertiente matérica que, más afianzada en el estudio crítico, nos permitirá pensar en términos de continuidad o ruptura.

\section{DESARROLLO}

El momento en el que Gerhard Richter decidió acariciar con su brocha la superficie húmeda de un cuadro para dar lugar a su hoy característico efecto de desenfoque marcó, señala David Barro ${ }^{5}$, el último punto de inflexión en la pintura reciente. Se iniciaba así un camino asiduamente recorrido luego por otros pintores-Celmins, Tuymans, Sasnal- embelesados por el aura irreal o el desperfecto de la imagen fotográfica como fuente de la pintura, el cual promovía una reflexión no tanto sobre la realidad sino sobre su representación. Así, mientras los cuerpos que artistas como Bacon, Tàpies o Millares estaban engendrando por aquel tiempo presentaban un estado lamentable inducido en parte por una realidad cargada de cadáveres, las figuras fantasmales de Richter y sus seguidores respondían a otro fallo, pero no de índole social o política sino eminentemente perceptiva o sensorial. Su indagación en los mecanismos de la representación evidenciaba la tensión entre la imagen mental de la memoria y la del artificio, y ponía en cuestión la veracidad de un medio -el fotográfico- que aún preservaba una reputación intachable de sinceridad. Quedaban así dos engaños al descubierto, el de la fotografía y el de la pintura que absurdamente la copia vaciándose. Lo real es la obra misma, la representación es mera ilusión.

Con la multiplicación hasta el infinito de dispositivos electrónicos en nuestro día a día el gesto de Richter atesora hoy el encanto nostálgico de una Polaroid. Seguimos fascinados por el fallo, y aunque el cambio de la tecnología analógica a la digital en busca de la perfección absoluta debería situarlo en peligro de extinción, lo cierto es que, de momento, sólo consigue mudar su aspecto. Era cuestión de tiempo que el arte centrara su mirada sublimadora en los accidentes provocados por el aluvión de píxeles que compone parte de nuestro imaginario actual. Lo que se ha denominado como arte glitch se fija en fallos transitorios que no afectan de manera decisiva al funcionamiento del sistema en que se originan, pero que interrumpen momentáneamente, de ahí la habitual frustración, el flujo de información. El término glitch llegó al arte en mitad de los 90 a través de la música ${ }^{6}$ y y fue la artista y teórica Rosa Menkman quien lo tomó para las artes visuales definiendo una estética del error extensible a nuestro entorno maquinizado: la nube de píxeles que recorre súbitamente la pantalla del televisor, las franjas de color saturado que impiden la lectura total de una imagen digital, el barrido fluctuante cual reflejo acuático en un monitor mal conectado... Estos accidentes se vuelven especialmente elocuentes sobre la

\footnotetext{
${ }^{3}$ Godfrey, Tony: La pintura hoy. Phaidon, Londres, 2010.

${ }^{4}$ Foster, Hal: El retorno de lo real. La vanguardia a finales de siglo. Akal, Madrid, 2001, p. 170.

${ }^{5}$ Barro, David: Antes de ayer y pasado mañana o lo que puede ser la pintura hoy. Museo de Arte Contemporáneo Unión Fenosa, La Coruña, 2009.

${ }^{6}$ Ajo, Pedro: La estética del error en la edad digital, 2014 [http://es.scribd.com/doc/196913083/La-estetica-del-error-en-la-edaddigital\#scribd]. [18 de abril de 2015]
} 
imagen de nuestro cuerpo, pues ofrecen nuevas maneras de desestabilizarlo, de quebrar su representación, de negar su integridad. Artistas glitch como Takeshi Murata, Michael Betancourt o la propia Menkman lo muestran en sus creaciones digitales. Será esta la mutilación más de una imagen que del cuerpo en sí: el icono abyecto, sangrante, da paso a una destrucción limpia, sin materia, sin mancha. La expresión pixel bleeding (sangrado de píxel), que hace referencia a un efecto provocado por un error en el código de la imagen digital, nos habla de cómo en cierto sentido la idea de herida persiste, pero ¿qué herida es esa?, ¿qué sangra el código de una imagen? La grieta nos revela el artificio, su alma de chip, nos hace despertar de la ilusión igual que lo hace la fotografía desenfocada.

Pero hablamos aquí de pintura, de materia que se mimetiza con lo intangible, con un error que no es propio de su lenguaje y que deja, por tanto, de ser error; es simulacro de error. Esta otra vuelta de tuerca al artificio de la imagen viene a reforzar una discusión abierta en el seno del arte glitch en su hábitat digital natural: la dialéctica entre el fallo accidental y el provocado nos posiciona frente al significado profundo de este fenómeno ¿Hacia dónde nos lleva el borrón virtual en la imagen del cuerpo? La idea más extendida otorga al accidente el rol de suceso por el cual "el instrumentalismo tecnológico incorpóreo de lo digital, que de otro modo es omitido de la consideración consciente por medio de las ilusiones vinculadas de perfección, transparencia e inmediatez, se hace evidente" ${ }^{7}$. Este razonamiento lleva implícita la imagen de una humanidad alienada inmersa en una existencia guiada más por simulacros de actos que por actos verdaderos. En ella el fallo nos alerta; la distorsión de un rostro nos dice que no es tal rostro, sólo su imagen. Pero ¿qué ocurre entonces cuando el fallo se fabrica? El accidente tiene sentido porque "humaniza la máquina alineándola con nuestra propia capacidad de errar. La máquina de alguna manera se vuelve menos amenazante cuando es vulnerable ${ }^{\prime 8}$. ¿No es fabricar el accidente una manera de hacerlo formar parte del mismo sistema ficticio? El ritmo vertiginoso de creación y desgaste que impone Internet revela ya una saturación por amaneramiento de ese arte glitch que para el purista pierde su sentido en la premeditación. En lugar de accidente habría que hablar más bien de atentado. El acercamiento de la pintura a la distorsión digital entraría en esta acepción: es accidente provocado y hecho además a imagen y semejanza de un proceder ajeno.

Veamos algunos ejemplos: la pintura del suizo Andy Denzler retrata a individuos ensimismados vistos a través de un velo de interferencias que imposibilita la nitidez de los cuerpos. La escasa definición de la imagen y la gama desaturada transmiten cierto aire retro, de televisor antiguo, de VHS. Ante estos cuerpos nos percatamos rápidamente de hallarnos ante una imagen plana, no tanto la del cuadro sino la de la pantalla descontextualizada. Denzler habla de resistencias que impiden el desarrollo de lo real en detrimento de lo abstracto ${ }^{9}$, y aquí la herencia de Richter se manifiesta insoslayable. No hay error pictórico, no hay accidente, es el ready made del error. Parecidas inquietudes comparte el chino Li Songsong, quien a partir de fotografías o capturas de vídeos difundidos por los medios de comunicación reflexiona sobre la memoria de su país. En su caso es la extrema densidad pictórica la que impide el detalle y el reconocimiento, ayudada por franjas de colores que a modo de impresión defectuosa filtran los motivos y terminan por situarlos en el limbo de la comprensión, ahí donde el poder de los medios de masa pretende arrastrarnos. De nuevo en el punto de mira la tensión entre la memoria o la percepción individual y el relato de los documentos oficiales ${ }^{10}$, y de nuevo, como en Denzler, tensión paradójica entre la desmaterialización que guía este estudio y la materialidad exaltada de sus pinturas, auténticos muros que fijan la fugacidad de cuerpos volátiles.

Parece haber llegado el momento para las nuevas generaciones de poner en entredicho la imagen mediática con la que han crecido, de ahí la evidente necesidad en no pocos pintores de problematizar el cuerpo no desde su experimentación física sino desde un ámbito representacional. Así lo hace Alejandro Bombín cuando nos acerca a la corrupción de la imagen en su proceso de almacenamiento, ya sea digital o mental: "Como nuestra memoria no tiene una capacidad infinita, la creación de nuevos recuerdos erosionará o sepultará el estrato en el que la imagen está grabada, de manera que cada vez será más inconsciente. Al volver a ella, nuestro cerebro tratará de darnos una imagen coherente, rellenando los huecos que falten, corrompiendo en cada intento la veracidad del recuerdo original” ${ }^{11}$. Esta idea se traduce en un proceso racionalizado que parte del escaneado en movimiento de páginas de revistas o libros antiguos. La imagen resultante, deformada por el desplazamiento y recortada en tiras, guía a Bombín en una rutina pictórica que le impide asistir al surgir de la obra. El enmascarado de las tiras ya pintadas dificulta el ajuste de las siguientes, causando sutiles imperfecciones alusivas a la pérdida de información en el cambio de un medio a otro. Figuras del pasado sepultadas en los estratos de la memoria reciben así un nuevo presente.

Pero es el estadounidense Benjamin Edwards quien llega a la más radical inmaterialidad adentrándonos en un espacio virtual que hace desaparecer la pantalla; no miramos la imagen, estamos en ella. Sus cuerpos se imbrican en un entorno intangible y cambiante de formas geométricas, signos y logotipos que siguen el movimiento de acusadas líneas de fuga. Modelados primero digitalmente mediante una combinación aleatoria de fragmentos corporales y texturas recogidas de Los Sims o Second Life y luego traducidos a pintura $^{12}$, los personajes flotan como entidades abstractas en una especie de no lugar virtual -se insinúan autopistas y centros

\footnotetext{
${ }^{7}$ Betancourt, Michael: Critical Glitches and Glitch Art, 2014 [http://www.hz-journal.org/n19/betancourt.html]. [22 de abril de 2015]

${ }^{8}$ Moradi, Iman: Seeking Perfect Imperfection: A personal retrospective on Glith Art, 2011 [http://virose.pt/vector/x_06/moradi.html]. [22 de abril de 2015]

${ }^{9}$ Ptak, Ulrich: "Defectos de la pintura". En Art.es, 2014, n 61 , pp. 47-54.

${ }^{10}$ Saatchi Gallery: Li Songsong, [http://www.saatchigallery.com/artists/li_songsong.htm]. [22 de abril de 2015]

${ }^{11}$ Bombín, Alejandro: Introducción, 2013 [http://www.alejandrobombin.com/]. [22 de abril de 2015]

${ }^{12}$ Wool, Lauren: Beautiful Mechanisms. A Conversation with Benjamin Edwards, 2013, [http://www.blunderbussmag.com/beautifulmechanisms-a-conversation-with-benjamin-edwards/]. [22 de abril de 2015]
} 
comerciales- que desmaterializa igualmente al espectador, porque Edwards nos presenta un mundo en el que nuestro cuerpo físico no tiene cabida. De este modo, bajo el dinamismo lúdico de sus composiciones subyace una inquietud: si con Denzler, Songsong y Bombín somos conscientes de asistir a una representación de nuestro cuerpo, con Edwards el simulacro es sumamente efectivo, pues sentimos como semejantes a seres que parecen nuestra versión futurista. Estos avatares, casi sin rostro, descompuestos en píxeles, carecen de voluntad frente al dominio de una conciencia superior dictatorial que les proporciona, como si de un videojuego se tratara, una falsa sensación de libertad. Es un dios tecnológico y a la vez el propio pintor quien ha creado un mundo propio de posibilidades, una utopía con lado oscuro cuyos habitantes reflejan la ansiedad del capitalismo desatado, del consumo como motor de vida y del empuje avasallador de lo tecnológico ${ }^{13}$.

La deificación de la tecnología que propone Edwards es el último escalón de una advertencia hacia la consecución de nuestros deseos: "¿Queremos desarrollo tecnológico? Aquí lo tenemos", parece decir el pintor, y también en cierta medida el resto de pintores mencionados y algunos otros que deberían tenerse en cuenta -como Kon Trubkovich o Emmet Kierans-. Internet ha mediatizado sobremanera nuestro modo de vida desmaterializando nuestra concepción del espacio y nuestras relaciones sociales. Como consecuencia de ello también el arte se ha visto afectado: el medio audiovisual "ha trastocado en última instancia todas las formas de la representación artística, gracias a esa repentina presentación en la que el tiempo real vence definitivamente al espacio real de las obras maestras" ${ }^{14}$. Hoy accedemos a la imagen de modo diferente, asistimos a su surgir en nuestras pantallas, al barrido vertical que nos la descubre poco a poco, a la transición de lo borroso a lo nítido durante el tiempo de carga. La imagen digital convierte en acontecimiento un aparecer que en la pintura física normalmente nos es negado. Puede hablarse, por tanto, de un tiempo y un movimiento presentes, y ninguno es ajeno al interés por lo incompleto y lo transitorio. La pintura que se hermana con el fallo digital enseña el nuevo cuerpo descompuesto de la sociedad, y es en contraste con lo que nos contó en el pasado que se vuelve elocuente: lo que ahora atenta contra nuestra integridad no es tanto la guerra o la enfermedad como el olvido total de nuestra fisicidad.

\section{CONCLUSIONES}

Mutilación física y mutilación digital: ambas comparten, en definitiva, su condición de falla en el sistema. Acercarnos al ecuador del siglo pasado nos descubre a pintores igualmente deseosos de un despertar. Los cuerpos heridos hechos de materia desbordante constituían el choque necesario. El accidente, nos dice Paul Virilio ${ }^{15}$, puede ser hoy la única alternativa al letargo, la última sorpresa que nos quede en la pretendida perfección digital. El accidente provocado, ese atentado que es la pintura de la que aquí hemos tratado de aportar algunas claves, se erige en manifestación de un dilema entre la fascinación estética que despierta el fallo y su poder contestatario. Si en un principio pudiera pensarse que la imitación del accidente digital supone claudicar ante el dominio del medio virtual, lo cierto es que se antoja finalmente una estrategia oportuna para propagar la incertidumbre hacia lo tecnológico mediante la apropiación de su mismo vocabulario. ¿Qué aporta entonces la pintura física al arte glitch digital? Dado que en cuanto al mensaje apreciamos una equivalencia, sólo su materialidad puede añadir algo a este artificio absurdo de imitaciones de simulacros: la paradójica reivindicación de lo manual que une a los pintores aquí destacados nos habla de la necesidad de estar de nuevo en contacto con la materia real de la que están hechas las cosas; ellos otorgan carnalidad pictórica a unos cuerpos que han quedado reducidos a poco más que apariciones fugaces en una pantalla. No es baladí en una era en la que se hace cada vez más patente la búsqueda de la asepsia absoluta. Es ahí donde el error constituye ciertamente un alivio, la prueba de que una saludable dosis de entropía se inmiscuye en el relato de construcción de la modernidad. Este nuevo cuerpo degradado revela su naturaleza icónica y artificial por medio del fallo, cuestionando de paso la veracidad de imágenes ciertamente engañosas en las que habíamos empezado a confiar ciegamente.

\footnotetext{
${ }^{13}$ Ibídem.

${ }^{14}$ Virilio, Paul: "Esperar lo inesperado”. En Seducidos por el accidente. Fundación Luis Seoane, La Coruña, 2005, p. 23.

${ }^{15}$ Ibídem.
} 


\section{FUENTES REFERENCIALES}

Ajo, Pedro: La estética del error en la edad digital, 2014 [http://es.scribd.com/doc/196913083/La-estetica-del-error-en-la-edaddigital\#scribd]. [18 de abril de 2015]

Barro, David: Antes de ayer y pasado mañana o lo que puede ser la pintura hoy. Museo de Arte Contemporáneo Unión Fenosa, La Coruña, 2009.

Barro, David et al: Muestra la herida. La enfermedad. Arte y medicina 1. Fundación Luis Seoane, La Coruña, 2010.

Betancourt, Michael: Critical Glitches and Glitch Art, 2014 [http://www.hz-journal.org/n19/betancourt.html]. [22 de abril de 2015]

Bombín, Alejandro: Introducción, 2013 [http://www.alejandrobombin.com/]. [22 de abril de 2015]

Calvo, Francisco et al: Pintura al desnudo. Picasso, Dubuffet, de Kooning, Bacon, Saura. Fundación BBVA, Bilbao, 2001.

Foster, Hal: El retorno de lo real. La vanguardia a finales de siglo. Akal, Madrid, 2001, p. 170.

Godfrey, Tony: La pintura hoy. Phaidon, Londres, 2010.

Moradi, Iman: Seeking Perfect Imperfection: A personal retrospective on Glith Art, 2011 [http://virose.pt/vector/x_06/moradi.html]. [22 de abril de 2015]

Ptak, Ulrich: “Defectos de la pintura”. En Art.es, 2014, no 61, pp. 47-54.

Saatchi Gallery: Li Songsong, [http://www.saatchigallery.com/artists/li_songsong.htm]. [22 de abril de 2015]

Virilio, Paul: “Esperar lo inesperado”. En Seducidos por el accidente. Fundación Luis Seoane, La Coruña, 2005, pp. 23-31.

Wool, Lauren: Beautiful Mechanisms. A Conversation with Benjamin Edwards, 2013, [http://www.blunderbussmag.com/beautifulmechanisms-a-conversation-with-benjamin-edwards/]. [22 de abril de 2015] 